\title{
Cost-effectiveness of video-assisted thoracoscopic surgery versus conservative treatment for first time or recurrent spontaneous pneumothorax
}

\author{
F.M.N.H. Schramel*, T.G. Sutedja*, J.C.E. Braber*, J.C. van Mourik**, P.E. Postmus*
}

Cost-effectiveness of video-assisted thoracoscopic surgery versus conservative treatment for first time or recurrent spontaneous pneumothorax. F.M.N.H. Schramel, T.G. Sutedja, J.C.E. Braber, J.C. van Mourik, P.E. Postmus. (CERS Journals Ltd 1996.

ABSTRACT: The aim of this study was to analyse differences in efficacy and costs in treating first time or recurrent spontaneous pneumothorax by conservative therapy (pleural drainage or observation) and video-assisted thoracoscopic surgery (VATS).

Retrospectively, 112 patients treated by conservative therapy during 1985-1989 (Period 1) were compared with 97 patients treated by VATS during 1991-1994 (Period 2). Mean follow-up time in each period was more than 2 yrs.

Patients in both periods had comparable clinical characteristics. Irrespective of first time or recurrent spontaneous pneumothorax at presentation, drainage and hospitalization times were longer, and complication and recurrence rates were higher in Period 1. When costs due to the waiting time before VATS were excluded, the total costs in Period 1 were higher than in Period 2.

Video-assisted thoracoscopic surgery is more effective in treating patients with first time or recurrent spontaneous pneumothorax, with less morbidity and total costs compared to conservative therapy. In view of cost-effectiveness, we feel that a different management of first time or recurrent spontaneous pneumothorax is not justified.

Eur Respir J., 1996, 9, 1821-1825.
Depts of *Pulmonary Diseases and **Surgery, Free University Hospital, Amsterdam, The Netherlands.

Correspondence: F.M.N.H. Schramel

Dept of Pulmonary Diseases

St. Antonius Hospital

PO Box 2500

3430 EM Nieuwegein

The Netherlands

Keywords: Pleural drainage spontaneous pneumothorax

video-assisted thoracoscopic surgery

Received: November 141995

Accepted after revision March 241996
Treatment of spontaneous pneumothorax is primarily aimed to remove air from the pleural cavity and to reduce the risk of possible recurrence [1]. To achieve these goals, numerous therapeutic options are available, ranging from simple observation to posterolateral thoracotomy with bullectomy and pleurectomy. Invasive procedures are recommended if the size of the pneumothorax exceeds $15 \%$ of the volume of the hemithorax, since the mean rate of spontaneous re-expansion of collapsed lung is only $1.8 \%$ per day, thus resulting in complete re-expansion without invasive treatments only after several weeks [2].

Thoracotomy with bullectomy and pleurectomy provides the lowest recurrence rates, varying from $0-3.6 \%$ [3-5]. However, treatment morbidity is high, in contrast to pleural drainage which carries a recurrence rate up to $40 \%[1,6,7]$. A relatively new approach is video-assisted thoracoscopic surgery (VATS). All surgical procedures which can be performed during thoracotomy are applicable during video-assisted thoracoscopy (VAT). VATS has proven its efficacy, with low recurrence rates ranging $0-13 \%$ and low morbidity compared to thoracotomy [8-14].

Usually, the choice of treatment depends on the patient's presentation with either a first time or recurrent spontaneous pneumothorax, the size of the pneumothorax, and the presence and extent of blebs and bullae $[1,5$, $15]$.
There are no studies available comparing the outcomes, complications, and costs between conservative therapy by pleural drainage or observation, and surgical management by VATS in patients with first time or recurrent spontaneous pneumothorax. Several previous studies have reported different results concerning the advantages in reducing health care costs by using video-assisted techniques in various lung diseases $[16,17]$.

The aim of this retrospective study was to analyse differences in efficacy and costs in treating first time or recurrent spontaneous pneumothorax by conservative therapy (pleural drainage or observation) or by VATS.

\section{Material and methods}

Until 1991, it was common practice at our department to treat patients with first time or recurrent spontaneous pneumothorax by pleural drainage or observation. No invasive procedures were performed if the size of the pneumothorax did not exceed $15 \%$ of the volume of the hemithorax and did not progress during observation. If the size of the pneumothorax progressed during observation or exceeded $15 \%$ of the volume of the hemithorax at presentation, pleural drainage was performed. Pleural drains were removed when the lung had been completely re-expanded and air leakage had ceased. Surgical treatment was performed if: air leakage persisted for more 
than 1 week; complications occurred requiring surgical intervention; or the pneumothorax relapsed. Surgical therapy consisted of axillary thoracotomy with bullectomy and pleural abrasion.

From 1991, all patients with first time or recurrent spontaneous pneumothorax were treated by VATS. VATS was performed in the operating room by a surgeon during general anaesthesia with double lumen intubation, multiple ports of entry and disposable instruments. If no blebs or bullae were present, pleurodesis was performed by talc poudrage. If blebs were present and bullae were smaller than $2 \mathrm{~cm}$, blebectomy and bullectomy were performed by electrocautery and pleurodesis by talc poudrage. These blebs and bullae were considered small. If bullae were larger than $2 \mathrm{~cm}$, bullectomy was performed with a stapling device (Autosuture Multifire EndoGIA ${ }^{\circledR}$ $3.5)$ and pleurodesis by pleural scarification. These bullae were considered large. Results of this approach have been published previously $[10,18,19]$.

\section{Data collection}

The medical records of all patients with first time or recurrent spontaneous pneumothorax admitted to our department during the periods 1985-1989 (Period 1) and 1991-1994 (Period 2) were retrospectively reviewed.

The following variables were recorded during both periods: primary treatment (observation or pleural drainage in Period 1, VATS in Period 2); complications; treatment of complications requiring intervention, such as drain dysfunction; persistent air-leakage; drainage time; and hospitalization time. Drainage time was the total time during which a pleural drain was present in order to re-expand the lung after primary treatment and, if necessary, after treating complications. Hospitalization time consisted of the time before primary treatment ("waiting time") and time after the primary treatment.

Follow-up was obtained by review of clinic records and telephone contact with the general practitioner or the

Table 1. - Tariffs (expressed in Dutch Florins) of the COTG (Government Health Insurance Tariff, April 1, 1995) used for the declaration of the therapeutic approaches by the hospital and the physician at the social health insurance fund and the private health insurance funds during both periods

\begin{tabular}{lrr}
\hline & \multicolumn{2}{c}{ Tariffs (Dutch Florins) } \\
& SHIF & PHIF \\
\hline Hospitalization per day & 763.00 & 709.00 \\
Pleural drainage & 623.16 & 648.00 \\
VAT with talc poudrage* & 863.56 & 998.00 \\
VATS with talc poudrage & 903.37 & 1103.00 \\
$\quad$ with or without coagulation** & & \\
$\begin{array}{l}\text { VATS with bullectomy** } \\
\text { Thoracotomy with bullectomy } \\
\text { pleural abrasion** }\end{array}$ & 2498.82 & 2725.00 \\
& 2459.01 & 2620.00 \\
\hline
\end{tabular}

*: local anaesthesia; **: general anaesthesia; tariffs declared by the anaesthesiologists are included. SHIF: social health insurance fund; PHIF: private health insurance fund; VAT: videoassisted thoracoscopy; VATS: video-assisted thoracoscopic surgery. patient. Costs were based on tariffs (expressed in Dutch florins) of the COTG (Government Health Insurance Tariff, April 1, 1995). Table 1 shows the tariffs of the COTG used for the declaration of the therapeutic approaches. The compound tariff was used to calculate the total costs during each period. The compound tariff is expressed as the sum of the weighed mean of the tariff declared by the physician at the social health insurance fund $(70 \%)$ and private health insurance funds (30\%), and the tariff declared by the hospital to cover expenses [20]. The total costs were expressed as the sum of costs of hospitalization time, of primary treatment and of treatment of complications. Hospitalization time during the period of treating recurrences had to be excluded because several patients were treated at other clinics.

\section{Statistics}

Differences of patient characteristics, complication rates, recurrence rates, drainage time, waiting time, hospitalization time and costs, between both periods and between patients with first time or recurrent spontaneous pneumothorax in each period were analysed by unpaired ttests and Chi-squared tests. A p-value of less than 0.05 was considered to be statistically significant.

\section{Results}

\section{Patients and treatments}

During periods 1 and 2, 112 patients and 97 patients, respectively, were admitted for first time or recurrent spontaneous pneumothorax. Patients with known underlying pulmonary disease were excluded. Table 2 shows the patient characteristics, which were similar in both groups.

During Period 1, 103 patients were treated with pleural drainage and 10 patients with observation. One patient was treated twice with pleural drainage because of contralateral pneumothorax.

During Period 2, all patients underwent VATS. Four patients were treated twice because of contralateral pneumothorax. Fifty patients were treated with talc poudrage, combined in 25 patients with electrocautery of small blebs and bullae. Fifty one patients were treated with bullectomy and pleural scarification.

Table 2. - Patient characteristics

\begin{tabular}{lccc}
\hline & Period 1 & Period 2 & p-value \\
\hline Patients n & 112 & 97 & \\
Age yrs & $35 \pm 14$ & $33 \pm 14$ & NS* $^{*}$ \\
Sex M/F & $88 / 24$ & $74 / 23$ & NS** $^{*}$ \\
Smokers n & 69 & 67 & NS** $^{*}$ \\
Recurrent SP n & 33 & 27 & Ns** \\
\hline
\end{tabular}

*: significance of unpaired t-tests; **: significance of Chisquared tests. NS: not significant; SP: spontaneous pneumothorax; M: male; F: female. 
Table 3. - Complications of all patients in both periods

\begin{tabular}{lccc}
\hline & $\begin{array}{c}\text { Period 1 } \\
(\mathrm{n}=112)\end{array}$ & $\begin{array}{c}\text { Period 2 } \\
(\mathrm{n}=97)\end{array}$ & $\mathrm{p}$-value* \\
\hline Recurrent SP & 21 & 4 & 0.002 \\
Drain dysfunction & 9 & 5 & NS \\
Atelectasis & 0 & 2 & NS \\
Pneumonia & 2 & 2 & NS \\
Empyema & 1 & 0 & NS \\
Re-expansion oedema & 0 & 2 & NS \\
Other & 0 & 3 & NS \\
\hline Total & 33 & 18 & 0.05 \\
\hline
\end{tabular}

*: significance of Chi-squared tests. SP: spontaneous pneumothorax; NS: not significant.

\section{Complications}

Table 3 shows the complications of all patients in both periods. The complication rate in Period $1(29 \%)$ was significantly higher than in Period $2(18 \%)(\mathrm{p}=0.05)$. There were no differences in complication rates between patients with first time and recurrent spontaneous pneumothorax in each period.

Follow-up could be obtained in 78 patients of Period 1 and of all patients in Period 2. The follow-up time of patients in Period 1 (96 \pm 18 months) was significantly longer than that of patients in Period 2 ( $29 \pm 10$ months) $(\mathrm{p}<$ $0.0001)$. Therefore, three kinds of recurrence rates in both periods were calculated: 1) overall recurrence rate after the total follow-up time; 2) one year recurrence rate after follow-up of $1 \mathrm{yr}$; 3) two year recurrence rate after follow-up of 2 yrs. In Period 1 and Period 2, the overall recurrence rate was 27 and 4\%, respectively, the one year recurrence rate was 19 and $3 \%$, respectively, and the two year recurrence rate was 22 and $4 \%$, respectively, $(p=0.001)$. Four of the 10 patients who were treated with observation in Period 1 had adequate follow-up. Two of these patients experienced recurrences.

In each period, the recurrences were proportionally divided amongst the patients with first time or recurrent spontaneous pneumothorax at presentation.

\section{Drainage time, waiting time and hospitalization time}

Table 4 shows the waiting time, drainage time and hospitalization time during each period. Drainage time of patients in Period 1 was significantly longer compared to patients in Period 2 ( $\mathrm{p}<0.0001)$.

There were no differences of drainage time between patients with first time and recurrent spontaneous pneumothorax in each period.

Table 4. - Waiting time before primary treatment, drainage time and total hospitalization time during Periods 1 and 2

\begin{tabular}{lccc}
\hline & $\begin{array}{c}\text { Period 1 } \\
(\mathrm{n}=112)\end{array}$ & $\begin{array}{c}\text { Period 2 } \\
(\mathrm{n}=97)\end{array}$ & p-value* \\
\hline Waiting time days & $0.8 \pm 3.0$ & $4.4 \pm 2.5$ & $<0.0001$ \\
Drainage time days & $9.4 \pm 6.9$ & $4.4 \pm 2.6$ & $<0.0001$ \\
Hospitalization time days & $13 \pm 10$ & $11 \pm 4$ & 0.03 \\
\hline
\end{tabular}

*: significance of unpaired t-tests.
Table 5. - Costs (expressed in Dutch Florins) per patient based on the compound tariff of treatments of patients with SP during Periods 1 and 2

\begin{tabular}{lccc}
\hline & \multicolumn{2}{c}{ Costs (Dutch Florins) } & \\
& Period 1 & Period 2 & p-value* \\
\hline Primary treatment & $586 \pm 182$ & $2403 \pm 805$ & $<0.0001$ \\
Hospitalization time & $+9629 \pm 7849$ & $+7926 \pm 3006$ & 0.03 \\
Complications & $+872 \pm 1165$ & $+91 \pm 395$ & $<0.0001$ \\
\cline { 2 - 4 } Subtotal & $11087 \pm 7275$ & $10420 \pm 3452$ & NS \\
Waiting time & $-588 \pm 2239$ & $-4558 \pm 3013$ & $<0.0001$ \\
\hline Total costs & $10499 \pm 7723$ & $5862 \pm 3013$ & $<0.0001$ \\
\hline
\end{tabular}

*: significance of unpaired t-tests. NS: not significant; SP: spontaneous pneumothorax.

Hospitalization time was significantly longer in Period 1 compared to Period $2(\mathrm{p}=0.03)$. Taking into account the waiting time in Period 2 (4.4 \pm 2.5 days), this difference became even larger $(\mathrm{p}<0.0001)$.

Patients with first time or recurrent spontaneous pneumothorax showed similar hospitalization time in each period.

\section{Treatments of complications}

Thirty two thoracotomies were performed during Period 1 for treating complications; 12 times for recurrent pneumothoraces and 20 times for persistent air-leakage. All other recurrences were treated by pleural drainage. None of the patients treated with thoracotomy experienced a recurrence.

Only one thoracotomy was performed during Period 2 for the treatment of a recurrent pneumothorax. One recurrence was treated with observation, one with drainage and one with repeated VATS. None of these patients had recurrence of the pneumothorax.

\section{Costs}

Table 5 shows the costs per patient, based on the compound tariff. If the costs for the waiting time in Period 2 were subtracted, the total costs in Period 1 were significantly higher than in Period 2, irrespective of the presentation with first time or recurrent spontaneous pneumothorax $(p<0.0001)$. Treatment of patients in Period 2 was $44 \%$ cheaper than treatment of patients in Period 1, when the costs for the waiting time were not considered.

Costs (Dutch Florins) of treating recurrences in Period $1(1,882 \pm 1,103)$ and Period $2(1,497 \pm 1,345)$ were not significantly different.

\section{Discussion}

Today, the choice of treatment of patients with spontaneous pneumothorax depends on the patient's presentation with a first time or recurrent pneumothorax, the size of the pneumothorax, and the presence and extent of blebs and bullae $[1,5]$. However, debate continues concerning which treatment modality is most appropriate in any of these patients $[2,8,21,22]$. The British Thoracic Society 
has published guidelines for the immediate and subsequent management of patients with spontaneous pneumothorax presenting to casualty departments [22]. Although pleural drainage had been standard treatment of pneumothorax, the guidelines were partly devised to avoid the insertion of poorly functioning intercostal tubes by inexperienced junior doctors. No distinction was made between patients with first time and recurrent spontaneous pneumothoraces and between patients without and with blebs and bullae.

Adequate removal of air from the pleural cavity and prevention of possible future recurrences are the main goals of any treatment in patients with spontaneous pneumothorax [1]. Conflicting opinions exist concerning what recurrence rate is acceptable after treating a spontaneous pneumothorax [15]. Which treatment is ultimately chosen depends on several factors, such as efficacy, morbidity, availability and costs of therapeutic modalities present in the clinic. Currently, cost-effectiveness is becoming more and more important for the choice of treatment in many situations.

In our retrospective study, it was possible to analyse the cost-effectiveness of two different treatment strategies in the management of first time and recurrent spontaneous pneumothorax. During the first period, conservative treatment, consisting of pleural drainage or observation and during the second period VATS was performed in all patients with spontaneous pneumothorax, irrespective of first time or recurrent spontaneous pneumothorax at presentation. Patients in both treatment periods were comparable regarding age, presentation with first time or recurrent spontaneous pneumothorax, and other risk factors for contracting a pneumothorax such as sex of the patient and smoking behaviour [1, 23, 24].

In the past, pleural drainage, simple aspiration and the use of a flutter valve proved to be safe, with minor sideeffects [6-8, 25-27]. However, recurrence rates were rather high, varying from $11 \%$ after aspiration up to $36 \%$ after pleural drainage. In our study, we confirmed this finding, demonstrating a recurrence rate of $27 \%$ after pleural drainage or observation. Even after a follow-up time of 1 and 2 yrs, the recurrence rates after conservative treatment were significantly higher than after VATS. As stated in the literature [8-10], our study showed that VATS is more effective with a recurrence rate of $4 \%$, less complications, shorter drainage and hospitalization time than pleural drainage or observation.

In view of the high recurrence and complication rate after pleural drainage or observation, one may doubt the efficacy of this strategy, because all patients with recurrences of spontaneous pneumothorax had to be admitted once again to the hospital for subsequent treatment, consisting of renewed drainage and even thoracotomy in $43 \%$ of the cases. On the other hand, one might argue that VATS is overtreatment in all patients that would not have experienced a recurrence after conservative treatment.

Based on the tariffs used in The Netherlands, costs of treatment per patient were not significantly different during both periods. However, in our hospital, the waiting time before VATS was responsible for a considerable part of the total cost of the surgical management. The waiting time, which is an important problem in many Dutch hospitals, is caused by a shortage of available operating time and financial budget. If waiting time could have been reduced, VATS might have been $44 \%$ cheaper than the conservative approach. The longer hospitalization time and higher complication rate were mostly responsible for the total costs of the conservatively treated patients.

Another factor influencing the total costs of VATS is the use of expensive disposable stapler devices necessary for bullectomy. However, the need for bullectomy in patients with spontaneous pneumothorax is questionable. Recently, we found that recurrences were not related to the presence and extent of blebs and bullae [18]. Therefore, effective pleurodesis plays a more prominent role in treating patients with spontaneous pneumothorax than bullectomy. Since talc poudrage can be performed during VAT under local anaesthesia in the endoscopy suite, this would result in further reduction of total costs [15]. If all patients with spontaneous pneumothorax had been treated with talc poudrage during VAT, this would have resulted in an additional $62 \%$ reduction of the treatment costs actually calculated for patients treated with VATS.

One of the indications to perform invasive procedures in spontaneous pneumothorax, such as pleural drainage with pleurodesis, VATS or even thoracotomy, is believed to be recurrent spontaneous pneumothorax at presentation $[1,5,15]$. However, in our study we could not find significant differences in recurrence rate, complication rate, drainage time, hospitalization time and total costs between patients with first time and recurrent spontaneous pneumothorax in each period. Therefore, in view of costeffectiveness; we feel it is not justified to treat patients with first time spontaneous pneumothorax in a different and less effective way than patients with recurrent spontaneous pneumothorax.

In conclusion, video-assisted thoracoscopic surgery is more effective in treating patients with first time or recurrent spontaneous pneumothorax, with less morbidity and total costs compared to conservative treatment by pleural drainage or observation.

\section{References}

1. Light RW. Pneumothorax. In: Light RW, ed. Pleural diseases. 3rd edn. Baltimore, Williams \& Wilkins, 1995; pp. 242-277.

2. Flint K, Hillawi AH, Johnson AM. Conservative treatment of spontaneous pneumothorax. Lancet 1984; i: 687-688.

3. Donahue DM, Wright CD, Viali G, Mathisen DJ. Resection of pulmonary blebs and pleurodesis for spontaneous pneumothorax. Chest 1993; 104 1767-1769.

4. Gobel WG, Rhea WG, Nelson IA, Daniel RA. Spontaneous pneumothorax. J Thorac Cardiovasc Surg 1963; 46: 331-345.

5. vd Brekel JA, Duurkens VAM, Vanderschueren RGJRA. Pneumothorax: results of thoracoscopy and pleurodesis with talc poudrage and thoracotomy. Chest 1993; 103: 345-347.

6. Harvey J, Prescott RJ. Simple aspiration versus intercostal tube drainage for spontaneous pneumothorax in patients with normal lungs. BMJ 1994; 309: 1338-1339.

7. Andrivet P, Djedaini K, Teboul JL, Brochard L, Dreyfuss D. Spontaneous pneumothorax: comparison of thoracic drainage $v s$ immediate or delayed needle aspiration. Chest 1995; 108: 335-340. 
8. Loddenkemper R, Boutin C. Thoracoscopy: present diagnostic and therapeutic indications. Eur Respir J 1993; 6: 1544-1555.

9. Hazelrigg SR, Landreneau RJ, Mack M, et al. Thoracoscopic stapled resection for spontaneous pneumothorax. J Thorac Cardiovasc Surg 1993; 105: 389-393.

10. Janssen JP, v. Mourik JC, Cuesta Valentin M, Sutedja G, Gigengack K, Postmus PE. Treatment of patients with spontaneous pneumothorax during videothoracoscopy. Eur Respir J 1994; 8: 1281-1284.

11. Radberg G, Dernevik L, Svanvik J, Thune A. A comparative retrospective study of thoracoscopy versus thoracotomy for the treatment of spontaneous pneumothorax. Surg Laprosc Endosc 1995; 5: 90-93.

12. Waller DA, Forty J, Morritt J. Video-assisted thoracoscopic surgery versus thoracotomy for spontaneous pneumothorax. Ann Thorac Surg 1994; 58: 372-377.

13. De Giacomo T, Rendina EA, Venuta F, Giriaco P, Lena A, Ricci C. Video-assisted thoracoscopy in the management of recurrent spontaneous pneumothorax. Eur J Surg 1995; 161: 227-230.

14. Weatherford DA, Stephenson JE, Taylor SM, Blackhurst D. Thoracoscopy versus thoracotomy: indications and advantages. Am Surg 1995; 61: 83-86.

15. Boutin C, Astoul P, Rey F, Mathur PN. Thoracoscopy in the diagnosis and treatment of spontaneous pneumothorax. Clin Chest Med 1995; 16: 497-503.

16. Hazelrigg SR, Nunchuck SK, Landreneau RJ, et al. Cost analysis for thoracoscopy: thoracoscopic wedge resection. Ann Thorac Surg 1993; 56: 633-635.

17. Molin LJ, Steinberg JB, Lanza LA. VATS increases costs in patients undergoing lung biopsy for interstitial lung disease. Ann Thorac Surg 1994; 58: 1595-1598.
18. Janssen JP, Schramel FMNH, Sutedja TG, Cuesta MA, Postmus PE. Videothoracoscopic appearance of first and recurrent pneumothorax. Chest 1995; 108: 330-334.

19. Schramel FMNH, Sutedja TG, Janssen JP, Cuesta MA, van Mourik JC, Postmus PE. Prognostic factors in patients with spontaneous pneumothorax treated with videoassisted thoracoscopy. Diagn Therap Endosc 1995; 2: $1-5$.

20. Ritsema GH, Polder JJ. Bij vermoeden van longembolie kan echografie van de beenvene onderzoek van eerste keuze zijn omdat het kosteneffectief is. Ned Tijds Gen 1995; 139: 1386-1390.

21. Kaiser LR. Video-assisted thoracic surgery: current state of the art. Ann Surg 1994; 220: 720-734.

22. Miller AC, Harvey JE, on behalf of Standards of Care Committee, British Thoracic Society. Guidelines for the management of spontaneous pneumothorax. BMJ 1993; 307: 114-116.

23. Jantz MA, Pierson DJ. Pneumothorax and barotrauma. Clin Chest Med 1994; 15: 75-91.

24. Bense L, Eklund G, Odont D, Wiman LG. Smoking and the increased risk of contracting spontaneous pneumothorax. Chest 1987; 92: 1009-1012.

25. Almind M, Lange P, Viskum K. Spontaneous pneumothorax: comparison of simple drainage, talc pleurodesis and tetracycline pleurodesis. Thorax 1989; 44: 627-630.

26. Spencer Jones J. A place for aspiration in the treatment of spontaneous pneumothorax. Thorax 1985; 40: 66-67.

27. Mercier C, Page A, Verdant A, Cossette R, Dontigny L, Pelletier LC. Out-patient management of intercostal tube drainage in spontaneous pneumothorax. Ann Thorac Surg 1976; 22: 163-165. 